\title{
O LAZER SÉRIO DE ROBERT A. STEBBINS
}

Recebido em: 28/08/2013

Aceito em: 30/01/2014

\author{
Saulo Neves Oliveira ${ }^{1}$ \\ Johannes Doll ${ }^{2}$ \\ Universidade Federal do Rio Grande do Sul(UFRGS) \\ Porto Alegre - RS - Brasil
}

RESUMO: O presente artigo visa apresentar o serious leisure, do sociólogo Robert A. Stebbins. Trata-se de uma proposição teórica sobre uma forma de lazer que, aliada a outras duas formas - casual leisure e project-based leisure -, constituem uma perspectiva teórica mais ampla. Apresentamos uma síntese de cada uma dessas três formas e acrescentamos um levantamento inicial que fizemos sobre os estudos brasileiros que se utilizaram dessa teoria em suas análises sobre atividades de lazer. O objetivo é oferecer dados iniciais para interessados em desenvolver estudos sobre o serious leisure ou mesmo sobre as outras duas formas de lazer. Também visamos acrescentar elementos que podem ser úteis às discussões sobre atividades que poucas vezes são enfocadas através de teorias classicamente utilizadas no Brasil. Por fim, tecemos nossas considerações sobre a relativa ausência de uma perspectiva sobre o lazer, a do serious leisure que entendemos como merecedora de atenção, compreensão e análise, visando incrementar amplamente o desenvolvimento e os debates sobre os estudos do lazer no Brasil.

PALAVRAS CHAVE: Trabalhadores Voluntários. Atividades de Lazer.

\section{SERIOUS LEISURES DE ROBERT A. STEBBINS}

ABSTRACT: This article presents the serious leisure, from Robert A. Stebbins. It is a theoretical proposition about a form of leisure that together with other two ways - casual and leisure project-based leisure - constitutes a broader theoretical perspective. We present a summary of each of these three forms and add an initial survey we did on Brazilian studies that used this theory in his analysis of leisure activities. Our goal is to provide baseline data for those interested in developing studies on the serious leisure or even on the other two forms of recreation. We also aim to add elements that may be useful to discussions of activities that are seldom focused through theories classically used in Brazil. Finally, we weave our considerations about the relative absence of a leisure perspective on what we understand as worthy of attention, comprehension and analysis, largely aimed at increasing the development and debates about leisure studies in Brazil.

KEYWORDS: Voluntary Workers. Leisure Activities.

\footnotetext{
${ }^{1}$ Professor de Educação Física, mestre em Educação, doutorando em Educação (UFRGS) e bolsista de doutorado CAPES

${ }^{2}$ Pedagogo e teólogo, professor associado na FACEd e PPGEdu (UFRGS).
} 


\section{INTRODUÇÃO}

Serious leisure é uma proposta conceitual de lazer do sociólogo canadense Robert A. Stebbins. São ainda poucos os estudos no Brasil que utilizam e abordam o conceito e, por isso, apresentamos este ensaio com o objetivo de introduzir o conceito de forma sintetizada aos interessados. Além disso, no presente artigo identificamos os estudos recentes sobre a temática no Brasil, o que pode servir para apontar possíveis caminhos de aprofundamento, debate crítico e desenvolvimento sobre o tema.

O serious leisure, traduzido por "lazer sério"3, como conceito surgiu entre 1973 e 1976, com as primeiras publicações de Robert A. Stebbins (2008). Importante destacar que é bem próximo desse momento, na década de 1980, que os estudos sobre lazer e recreação no Brasil começam a ganhar consistência, a partir da ampliação de sua produção acadêmico-científica, de acordo com Peixoto (2007). De fato, o campo de estudos sobre o lazer em geral é relativamente recente tendo o início de estudos mais sistemáticos somente a partir da metade do século XX (PRAHL, 2002).

Em uma pesquisa que fazia sobre a relação entre amadores e profissionais, Stebbins estranhou a forma como os participantes se posicionavam frente ao senso comum de lazer. Os participantes, considerados amadores, faziam questão de deixar claro ao pesquisador que as atividades que praticavam não eram lazer. De acordo com os pesquisados, as atividades eram sérias, em que havia uma participação diferenciada com alto comprometimento, diferente do que as pessoas faziam "por lazer".

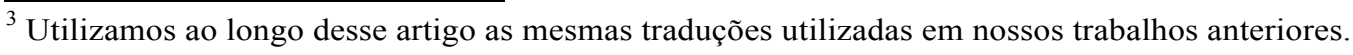


Esse posicionamento observado gerou mudanças na investigação de Stebbins, visto que as teorias clássicas sobre o lazer sobre as quais ele se baseava não davam conta do elemento "seriedade" fortemente associado pelos participantes às atividades que praticavam (STEBBINS, 2008, p.101). Tais teorias posicionavam o lazer em contraposição ao trabalho, uma semelhança que poderia ser observada também nos estudos de lazer no Brasil, fortemente influenciados pelos pensamentos formulados por Dumazedier na década de 1970 (GOMES, 2008).

Desde então, Robert A. Stebbins voltou sua atenção às atividades de lazer caracterizadas por esse tipo de seriedade e desenvolveu o "lazer sério" como conceito. No Brasil, a seriedade não é algo impensado. Temos estudos como os de Stigger (1997; 2007), por exemplo, que tratam especialmente de como o lazer assume uma dimensão "séria", significativa da vida dos jogadores de futebol de várzea.

Stebbins formulou no mesmo período, um conceito que se opunha ao de "lazer sério", o de "lazer casual”. Essa formulação servia para auxiliá-lo na explicação do "lazer sério", a partir dos contrastes que identificou entre os dois tipos de lazer. Somente a partir da década de 1990 que o conceito recebeu atenção acadêmica (STEBBINS, 2008, p.37). E, décadas depois, com uma longa jornada de pesquisas sobre o lazer, Stebbins propôs o que chamou de "lazer baseado em projeto".

Nos últimos anos, Robert Stebbins denominou o conjunto formado por essas três formas de lazer "Perspectiva do Lazer Sério" (STEBBINS, 2008, p.101). O nome pode gerar confusão e até dificuldades para a comunidade acadêmica do Brasil, pois não se refere apenas do "lazer sério", mas às três formas mencionadas anteriormente, ainda pouco conhecidas pelos pesquisadores brasileiros (OLIVEIRA \& DOLL, 2012). 
De acordo com Stebbins, a escolha do nome da "Perspectiva" deu-se pela familiaridade que a comunidade acadêmica já tinha com o nome "lazer sério", o que ajudou em sua proposta. Stebbins chama atenção para o fato de que a presença do termo "lazer sério" no nome da "Perspectiva" não quer dizer que o "lazer sério" seja mais importante que as outras formas de lazer possíveis (STEBBINS, 2008, p.05). No fundo, trata-se de uma proposta teórica que estrutura as atividades de lazer e seu nome contém a primeira forma de lazer que Stebbins estudou.

Passamos então, a apresentar o "lazer sério", sua definição e características básicas. Em seguida, mencionamos a produção acadêmica utilizando o conceito de "lazer sério" no Brasil que conseguimos encontrar e oferecemos breves apontamentos e, ao final, fazemos nossas considerações.

\section{O LAZER SÉRIO}

Como mencionamos anteriormente, "lazer sério" foi o conceito que recebeu mais atenção durante a maior parte do tempo das produções científicas de Robert A. Stebbins. É possível verificar isso tanto na afirmação do autor (STEBBINS, 2008, p.37), quanto na observação da lista de publicações de livros do autor. Robert A. Stebbins define o "lazer sério" com a seguinte declaração:

\footnotetext{
[...] a prática sistemática de uma atividade central por amadores, praticantes de hobby ou voluntários, considerada substancial, interessante e realizadora, que em casos típicos, lança-lhes numa carreira (de lazer) centrada na aquisição e expressão de uma combinação de habilidades especiais, conhecimento e experiência (modificado de STEBBINS, 1992, p.3, apud STEBBINS 2008, p.5, tradução nossa).
}

Na tentativa de elucidar a definição de Stebbins (2008), destacamos termos que consideramos chave para o entendimento de sua proposta. Em primeiro lugar o termo “atividade central", que aparece na definição de "lazer sério". Stebbins entende a 
"atividade central" como "uma configuração de ações ou passos inter-relacionados que devem ser seguidos para obter os resultados ou produtos que os participantes procuram" (STEBBINS, 2012, p.07).

As "atividades centrais" possuem níveis de complexidade que variam entre menos e mais complexas. Um importante aspecto contido na teoria de Stebbins (2012) sobre o "lazer sério" reside no fato de que sua "atividade central" situa-se no polo mais extremo de complexidade. As "atividades centrais" são alvo no trabalho, lazer e obrigações não profissionais e podem ser exemplificadas no "lazer sério" como: o correr, entre praticantes de corridas de rua; o selecionar e compor uma coleção, na filatelia; e, o ajudar nos cuidados e doação de animais, em serviços voluntários. Nos três casos, os participantes têm ações diferentes para, com sucesso, correr, colecionar, ou ajudar animais.

Propositalmente, os exemplos de "atividades centrais" apresentados foram dados dentro das três modelos de possíveis praticantes do "lazer sério", encontradas na definição de Stebbins (2008), respectivamente: amadores, praticantes de hobby e voluntários. Amadores são encontrados nas artes, ciências, esportes e entretenimento, áreas em que estão inevitavelmente ligados de diferentes formas a seus pares profissionais. Praticantes de hobby não tem esse alterego profissional, e podem ser classificados em uma de cinco categorias: colecionadores, fabricantes e construtores, participantes de atividade (em atividades não competitivas, baseadas em regras), jogadores e esportistas (onde não existem homólogos profissionais), e entusiastas em uma das artes liberais (STEBBINS, 2006).

O terceiro modelo padrão a que Stebbins (2008) se refere em sua definição para o "lazer sério" é o voluntário. Voluntário é aquele que realiza, mesmo que durante um 
período curto, trabalho voluntário. Em sua definição, é através do trabalho voluntário que essa pessoa oferece um serviço ou benefício a um ou mais indivíduos (fora de sua própria família), normalmente sem receber qualquer pagamento, ainda que possam receber ajuda de custo ao participarem em alguns programas de voluntariado (STEBBINS, 2012, p.71). O elemento chave na concepção do voluntariado como lazer, de acordo com Stebbins (2012, p.71), é a "ausência da coersão, moral ou qualquer outro tipo" para participar das atividades de voluntariado.

Na concepção adotada por Stebbins (2012), as atividades voluntárias são motivadas, em parte, por um dentre seis tipos de interesses: interesses em atividades que envolvam (1) pessoas, (2) idéias, (3) coisas, (4) flora, (5) fauna, ou (6) o meio ambiente (STEBBINS ${ }^{4}, 2007 \mathrm{~b}$ apud STEBBINS, 2012, p.71). Na interseção entre a dimensão dos interesses, motivacional, e a contextual, Stebbins (2012) identifica "18 tipos de voluntários e voluntariados", buscando explicar esse modelo dentro da "Perspectiva do Lazer Sério".

Podemos destacar ainda na definição de Robert A. Stebbins de "lazer sério", a “carreira de lazer" para a qual estes modelos de praticantes - amadores, praticantes de hobby e voluntários - podem ser "lançados". Para Stebbins (2008, pp.13-17), a "carreira" é um curso típico, ou passagem, através de uma atividade de lazer, que não apenas molda a busca contínua por certas recompensas, como também é moldado por ela. O conceito de "carreira" segue, de acordo com Stebbins (2012, p.69) a tradição sociológica para a qual ela está presente em todos os papéis sociais substanciais e complexo, incluindo o lazer. Além disso, a "carreira de lazer" é o maior recurso de motivação para continuar realizando a atividade (STEBBINS, 2012, p.14).

\footnotetext{
${ }^{4}$ STEBBINS, Robert A. A leisure-based, theoretic typology of volunteers and volunteering. Leisure Studies Association Newletter, 78 (Nov.), $2007 \mathrm{~b}$.
} 
A centralidade da carreira de lazer expressa na "aquisição e expressão de uma combinação de habilidades especiais, conhecimento e experiência" (STEBBINS, 2008, p.05), incorpora à definição do "lazer sério" os sentidos como de comprometimento, empenho e seriedade presentes nas práticas de lazer que Stebbins pretende enfocar. Ainda, nos ajudam a entender o que Robert A. Stebbins chamou de "seis qualidades distintivas" do "lazer sério" (2006, p.450).

\section{AS SEIS QUALIDADES DISTINTIVAS DO LAZER SÉRIO}

Robert A. Stebbins (2008, pp.11-13) identificou "seis qualidades" do "lazer sério" que o distinguem entre todas as possíveis formas de lazer. De acordo com Stebbins (2008), é possível que sejam observadas combinações dessas qualidades em outros tipos de lazer. Porém, é somente no "lazer sério" que essas qualidades apresentam-se em sua totalidade (2008).

"Perseverança" é a primeira qualidade do "lazer sério" apresentada. Stebbins (2008) define a "perseverança" como uma necessidade ocasional que surge e se apresenta aos praticantes do "lazer sério" em casos em que enfrentam situações adversas decorrentes de suas práticas. Podemos considerar como exemplo, o caso de praticantes de corridas de rua que pesquisamos (OLIVEIRA, 2010). Alguns corredores enfrentavam na época situações temporariamente limitantes em que não podiam correr porque estavam lesionados, precisavam fazer um treino adaptado para permitir e promover uma recuperação rápida para que pudessem logo voltar às atividades. Essa urgência se dava por conta do tempo de treinamento necessário para que atingissem as “marcas" (tempos) que desejavam e obtivessem os benefícios que estavambuscando. 
Poderíamos considerar a presença dessa qualidade em outros campos, fora do esportivo. A "perseverança" é observada quando um voluntário ou seu grupo, por exemplo, enfrentam dificuldades ao tentar ajudar outros - sendo ofendidos por moradores de rua para quem tentam entregar agasalhos ou comida; enfrentando dificuldades como chuva ou mesmo a falta de equipamentos e materiais que permitam uma oferta melhor de seu serviço.

Essa primeira qualidade, a "perseverança", é considerada por Stebbins (2008) o "motor" que impulsiona a segunda qualidade identificada. A "carreira" está ligada a continuidade na atividade, tanto em períodos de aumento de prestígio e benefícios, quanto na diminuição destes. Quatro estágios estão presentes na "carreira" e ocorrem de forma imprecisa: o de iniciação, em que os praticantes adquirem as habilidades ou conhecimentos específicos da atividade de lazer; o desenvolvimento, em que os praticantes aprimoram essas habilidades ou conhecimentos; o estabelecimento, em que os praticantes do lazer alcançam relativa estabilidade em suas habilidades e conhecimentos; o estágio de manutenção, em que os praticantes buscam manter suas habilidades e conhecimentos nos mais altos níveis; e o declínio e afastamento. Os últimos estágios nem sempre estão presentes, porém são típicos nos casos em que participantes apresentam um declínio de suas habilidades físicas ou mentais.

Durante a "carreira", considerada qualidade central do "lazer sério", os praticantes precisam empenhar um "esforço substancial" para desenvolverem seu conhecimento, treino, experiência ou habilidades, a terceira qualidade. A qualidade “esforço substancial" poderia ser observada, por exemplo, quando um cantor amador empenha-se em desenvolver as habilidades necessárias para que execute um trecho 
musical difícil, treinando para isso, fazendo aulas com professores especialistas, organizando sua rotina diária e orçamento financeiro em torno de seu objetivo.

Como retorno do empenho em desenvolver conhecimento, treino, experiência ou habilidades, os participantes são beneficiados tanto emocional quanto socialmente. $\mathrm{Na}$ continuidade da "carreira" e, a partir dos avanços percebidos pelos praticantes do "lazer sério", pode ser percebida essa outra qualidade do "lazer sério", a presença dos “benefícios duráveis". Nessa quarta qualidade encontram-se benefícios como reconhecimento e integração social, melhoria da auto-imagem, entre outros.

A quinta qualidade apresentada por Robert A. Stebbins é chamada de "etos único" ou "etos exclusivo", que se refere ao "mundo social específico" que se desenvolve em torno das práticas em torno do desenvolvimento do "lazer sério". Essa qualidade é evidente na comunidade de praticantes de "lazer sério" em seu “compartilhar de atitudes, práticas, valores, crenças, objetivos, e assim por diante" (STEBBINS, 2008, p.12). Stebbins (2008) baseia sua proposta de "mundo social" nas concepções desenvolvidas por Unruh $\left(1979^{5} ; 1980\right.$, apud STEBBINS, 2008, p.12). Vale a pena mencionar a parte inicial de seu artigo:

\begin{abstract}
A noção de mundos sociais é utilizado aqui para referir uma forma de organização social que não pode ser precisamente demarcada por fronteiras espaciais, territoriais, formais, ou de membresia. Antes, as fronteiras dos mundos sociais devem ser determinadas pela interação e comunicação que transcendem e atravessam os mais formais e tradicionais delineadores de organização (UNRUH, 1980, p.271, tradução nossa).
\end{abstract}

Stebbins (2008) destaca a concepção de um "mundo social difuso e amórfico" que, de acordo com Unruh (1980, p.277), “deve ser visto como uma constelação reconhecível de atores, organizações, eventos e práticas que se aderem à esfera de interesse e envolvimento dos participantes" (UNRUH, 1980, p.277, apud STEBBINS,

${ }^{5}$ UNRUH, David R. Characteristics and types of participation in social worlds. Symbolic Interaction, v. 2, n. 2, p. 115-130, 1979. 
2008, p.12, tradução nossa). Ao compartilharem desse mundo social, os participantes do "lazer sério" tendem a identificarem-se fortemente uns com os outros, caracterizando a última qualidade distintiva do lazer sério: a "identificação" (STEBBINS, 2008, p.1213). Essa qualidade do "lazer sério" emerge das outras cinco qualidades e, de acordo com Stebbins (2012, p.13) as realizações no "lazer sério" podem ter um apelo identificador maior que um papel profissional de uma pessoa.

Com essas seis qualidades, é possível distinguir o "lazer sério" de outros tipos de lazer, especialmente dos outros dois tipos de lazer identificados e conceitualmente propostos por Robert A. Stebbins (2008): o "lazer casual" e o "lazer baseado em projeto". O "lazer sério" pode ser considerado o carro-chefe, não por ter mais importância, mas por ter sido o gerador de questionamentos que levaram ao desenvolvimento teórico das outras duas formas de lazer (STEBBINS, 2008).

\section{LAZER CASUAL E LAZER BASEADO EM PROJETO}

Ao lado do "lazer sério", Stebbins (2008) posicionou o "lazer casual" e o "lazer baseado em projeto" ${ }^{\text {, }}$ como dois tipos possíveis de lazer. Importante salientar que não se trata de um "mapa tipológico do mundo do lazer" (STEBBINS, 2008, p.3), embora Robert A. Stebbins entendesse que todo o lazer na sociedade ocidental poderia ser classificado de acordo com uma das três formas identificadas por ele.

Podemos destacar algumas características principais de cada um desses lazeres. De acordo com Stebbins, "lazer casual" como um conceito surgiu com o "lazer sério", porém, somente a partir dos anos 90 que esse tipo de lazer foi mais discutido teoricamente. Stebbins (2008) considerava "lazer casual" como "todo o lazer não

\footnotetext{
${ }^{6}$ Casual leisure e Project-based leisure, respectivamente.
} 
classificado como de amadores, praticantes de hobby ou voluntários" (STEBBINS ${ }^{7}$, 2001b, p.305 apud STEBBINS, 2008, p.43), uma concepção que mereceu ser revista e reformulada, posteriormente.

"Lazer casual é uma atividade imediata, de valor intrínseco, com satisfação relativamente curta, que requer pouca ou nenhuma habilidade especial para ser aproveitada" (STEBBINS, 2008, p.38, tradução nossa). Robert A. Stebbins lista oito tipos de atividades que, segundo ele, podem ser consideradas de "lazer casual": jogo, relaxamento, entretenimento passivo, entretenimento ativo, conversação social, estimulação sensorial, voluntariado casual e atividades aeróbicas (STEBBINS, 2008, p.39). Stebbins (2008) destaca que esses tipos de atividades se apresentam de forma combinada, havendo pelo menos duas das atividades ocorrendo simultaneamente. A característica comum presentes nas atividades é o hedonismo, ou seja, essas atividades produzem um significante nível de prazer a contentamento para os participantes.

De acordo com Stebbins (2008), em relação à sua complexidade, o "lazer casual" e o "lazer sério" localizam-se em "dois pólos opostos de um continuum" (STEBBINS, 2008, p.49, tradução nossa). Em matéria de complexidade, entre esses dois tipos de lazer, encontra-se o "lazer baseado em projeto", que é definido como:

[...] a tarefa criativa, excepcional ou ocasional, pouco freqüente, no tempo livre, que requer planejamento e esforço consideráveis e algumas vezes, habilidades e conhecimento, mas em que, diferente do "lazer sério", não há intenção pelos participantes em se desenvolver nisso [ou melhor, nessas qualidades presentes] (STEBBINS, 2008, p.43, tradução nossa).

O "lazer baseado em projeto" engloba atividades relacionadas, tanto a atividades regulares como aniversários, festas de fim-de-ano, festivais religiosos, etc. - que

\footnotetext{
${ }^{7}$ STEBBINS, Robert A. The costs and benefits of hedonism: Some consequences of taking casual leisure seriously. Leisure studies, v. 20, n. 4, p. 305-309, 2001 b.
} 
Stebbins (2008) classificou como "projetos ocasionais". Quanto a atividades relacionadas ao envolvimento na proposição e organização de eventos que ocorrem excepcionalmente, como alguns eventos esportivos, aniversários surpresa, festas de confraternização, etc., classificados como "projetos excepcionais" (STEBBINS, 2008, 44-47).

Além de definir o "lazer baseado em projeto", Robert A. Stebbins (2008) acrescenta características que auxiliam na identificação desse tipo de lazer. Para que as atividades de um projeto sejam qualificadas como "lazer baseado em projeto" é necessário que ao "criador do projeto" estas atividades sejam fundamentalmente nãocoercivas e de satisfação. Em contraste com o "lazer sério", o "lazer baseado em projeto", de acordo com Stebbins (2008, p.45), não apresenta um senso de carreira, porém é possível notar a presença de outras qualidades que o aproximam do "lazer sério".

No "lazer baseado em projeto", há a necessidade de "perseverança" e algumas habilidades e conhecimentos são requeridos e expressos. Pode-se observar a presença do “esforço" por parte dos participantes e também estão presentes os "benefícios duráveis", a "identificação" entre os participantes e, com isso, o desenvolvimento um "mundo social” - para Stebbins (2008, p.75), bastante rudimentar.

Um aspecto que Stebbins (2008) ressalta no desenvolvimento da concepção de "lazer baseado em projeto" é a possibilidade de seus participantes se sentirem fortemente atraídos a buscar um "lazer sério", a partir do desenvolvimento de uma “carreira". Ainda, Robert Stebbins sugere que o "lazer baseado em projeto" oferece pelo menos duas formas possíveis para o desenvolvimento comunitário. O primeiro, a partir do encontro de pessoas que não teriam contato por outras razões. O segundo, por vias de 
voluntariado e outras atividade altruístas, contribuindo com eventos e projetos comunitários (STEBBINS, 2008, p.45).

\section{ESTUDOS SOBRE LAZER SÉRIO NO BRASIL}

Muitos estudos têm sido desenvolvidos a partir da chamada "Perspectiva do Lazer Sério" ao redor do mundo e começam a aparecer, com maior frequência nos últimos anos, alguns estudos no Brasil. Como forma de oferecer um breve panorama, apresentamos um levantamento sobre trabalhos em desenvolvimento, produzidos e publicados sobre o assunto no $\mathrm{Brasil}^{8}$.

O estudo mais antigo que conseguimos identificar utilizando a teoria de Robert A. Stebbins como referência foi o do pesquisador Bramante (1999; 2004 ${ }^{9}$, apud STEBBINS, 2008, p.127), em um trabalho com o voluntariado de jovens em Sorocaba, no Brasil. Encontramos o artigo a partir da menção feita por Stebbins (2008) no livro em que apresenta a "Perspectiva". Bramante utiliza em seu estudo o termo "lazer levado a sério" para traduzir o "serious leisure" e referir-se ao tipo de atividade voluntária que investigou.

O segundo estudo mais antigo que conseguimos identificar foi publicado por Costa (2000), analisando praticantes de esportes na natureza e utilizando especialmente a "carreira" do "lazer sério" para elucidar os sentidos da aventura e risco em suas

\footnotetext{
8 A pesquisa baseou-se em dados publicados pelos autores em seus currículos na Plataforma Lattes. Disponível em: www.lattes.cnpq.br. Acesso em: 07 ago. 2013; nas referências de publicações oferecidas no site de Robert A. Stebbins. Disponível em: www.seriousleisure.net. Acesso em: 07 ago. 2013 e um de seus livros (STEBBINS, 2008); e, nos resultados de buscas do Google Scholar e Google Books utilizando como termos-chave: "serious leisure", "lazer sério", e "lazer levado a sério".

${ }^{9}$ BRAMANTE, Antônio Carlos. Fostering human resources in the leisure field: "Serious leisure" and the potential role of volunteers. A proposal for developing countries. In: STEBBINS, R.A; GRAHAM, M.M. (Ed.). Volunteering as leisure/leisure as volunteering: An international assessment. (pp.225-240). Wallingford, Oxon, UK: CAB International, 2004.
} 
práticas. Mais tarde, em 2005, Costa publicou um ensaio sintetizando algumas das questões abordadas anteriormente (COSTA, 2005).

Um ano depois, em um congresso, Stadnik, Cunha \& Pereira (2006) apresentaram um artigo focado no desenvolvimento da ginástica na educação física escolar a partir de práticas baseadas em princípios para uma educação visando o "lazer sério" e o "lazer casual". No mesmo ano de 2006, Stadnik publicou em livro um capítulo em que discute a prática de ginástica como um "lazer sério" (STADNIK, 2010) ${ }^{10}$. Cabe destacar que mais tarde, em 2008, Stadnik voltou a utilizar o "lazer sério" como conceito nas análises sobre práticas e representações de professores de educação física, em sua tese de doutorado, na Universidade do Minho, em Portugal.

Ainda em 2008, foi publicada a dissertação de Teixeira (2008), sobre os participantes da organização de uma festa folclórica no município de São Luíz, Maranhão, utilizando o "lazer sério" como conceito básico para entender o fenômeno pesquisado. Importante destacar que houve trabalhos de Teixeira juntamente com seus colegas e orientadora publicados como resumos em anais de congresso antes e depois de sua dissertação, todos em torno do mesmo estudo sobre a festa do "Bumba-meu-boi" (TEIXEIRA et al., 2007; TEIXEIRA, 2009).

Lacerda e Veiga (2008) utilizam o mesmo conceito para ampliar as discussões entre as relações do profissional do lazer com o marketing. No mesmo ano, não no Brasil, mas também em português, podemos mencionar a tese de doutorado de Stadnik (2008), concluída na Universidade do Minho, utilizando o termo "lazer sério" como um dos conceitos que perpassam a formação de docentes da educação física.

${ }^{10}$ O livro foi reeditado em 2010. 
A resenha "Serious Leisure" (OLIVEIRA \& DOLL, 2012), de nossa autoria, foi a mais recente publicação identificada em nossa pesquisa. Na resenha, buscamos sintetizar os conteúdos do livro "Serious Leisure: a perspective for our time" (STEBBINS, 2008), propondo o trabalho como forma introdutória à "Perspectiva do Lazer Sério", já que não há qualquer livro de Stebbins no idioma português. Mesmo se tratando de uma resenha, a publicação apresenta um conteúdo mais amplo relacionado à "perspectiva" do que os trabalhos anteriores e uma breve crítica.

Dentre os estudos relacionados ao "lazer sério" mais recentes que encontramos, identificamos dois projetos de pesquisa que estão em desenvolvimento no Brasil. Um deles é o chamado "1982-2012 - 30 years of Serious Leisure”, proposto por Carnicelli Filho $(2012)^{11}$ e objetiva analisar os mais de 30 artigos publicados por Robert Stebbins utilizando a "Perspectiva do Lazer Sério" e 5 horas de entrevistas em profundidade com o autor.

O segundo projeto, "Envelhecimento e Educação ao Longo da Vida na Perspectiva do Lazer Sério", está sendo desenvolvido por um grupo de pesquisa formado da parceria entre as faculdades de educação e educação física da UFRGS. O projeto tem o objetivo de traduzir, adaptar e analisar as potencialidades de um instrumento proposto por Gould, et al. (2008) para analisar as "qualidades distintivas do lazer sério".

Ao pensarmos sobre as possibilidades de inclusão da "Perspectiva do Lazer Sério" ou de algum de seus conteúdos em debates nacionais e mesmo latino-americanos dos estudos do lazer, podemos identificar diferentes desafios que se apresentam. A ausência de publicações em português da "Perspectiva do Lazer Sério" dificulta

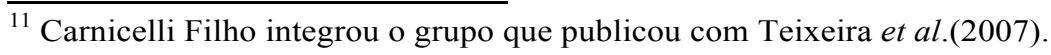


diálogos entre suas proposições e as proposições presentes nos estudos atuais do lazer em âmbito nacional e latino-americano. Mesmo olhando para as publicações em inglês, nos parece que para entender a proposta de Robert A. Stebbins de maneira profunda é necessária a leitura atenta e sistemática de muitas dessas publicações. Em geral, há conceitos que carregam conteúdos complexos e são apresentados em publicações específicas sobre eles. Os mesmos conceitos aparecem em outras publicações juntamente com outros que não apresentam o mesmo nível de poder explicativo que contemplem sua complexidade evidente na própria proposta de Stebbins.

Tratando-se de complexidade, a "Perspectiva" ao mesmo tempo em que indica interfaces complexas do lazer e do trabalho, a seriedade, a "apropriação do tempo livre" a partir de uma lógica do capital, entre outras, ela parece oferecer enquadramentos limitantes na forma de olhar o lazer - como, por exemplo, os tipos de praticantes, por exemplo, (BRABHAM, 2012), a intensidade de envolvimento e que atividades podem ser consideradas pertencentes a cada tipo de lazer, por exemplo, (ARAI \& PEDLAR, 2003), entre outras. Em outras palavras, embora as análises empíricas que sustentam tais proposições contemplem essa complexidade - a maioria em trabalhos etnográficos, com entrevistas em profundidade -, as sínteses conceituais e as classificações propostas não parecem dar conta de expressar sua profundidade.

Outra dificuldade, especificamente sobre a teoria, está na ênfase maior dada ao "lazer sério" entre os outros dois tipos de lazer ("lazer casual" e "lazer baseado em projeto"). Stebbins (2008) reconhece essa valorização como uma consequência negativa de suas tentativas iniciais de explicar o "lazer sério" a partir da oposição com o "lazer casual" - um construto que, na época, tinha fundamentalmente apenas essa finalidade. Dada a tradição de estudos do lazer brasileira que dá ênfase a conteúdos mais próximos 
do "lazer casual", a "Perspectiva" (do "lazer sério") e seus conteúdos podem parecer pouco interessantes e não despertar grande interesse temático.

Um fato interessante sobre a proposta de Stebbins é que é possível perceber sua abertura para críticas e contribuições. A teoria do lazer sério está inacabada, um aspecto facilmente identificado nas leituras. Stebbins (2008) apresenta as contribuições diretas de outros autores e se mostra disposto a incluir novas contribuições de diferentes pesquisadores $^{12}$.

\section{CONSIDERAÇÕES FINAIS}

A questão da seriedade, um aspecto importante incluído na concepção do "lazer sério", não é nova no contexto brasileiro. É possível notar, porém, que o "lazer sério" não entra em discussão entre os conceitos que fazem parte do grande debate. A proposta de Robert A. Stebbins não é nova, pelo contrário, tem sido elaborada durante décadas. Embora seja ainda pouco conhecida no Brasil e América Latina, consideramos uma proposta consistente e de alta potência, capaz de gerar debates interessantes e fecundos. Especialmente sobre os sentidos dados às atividades de lazer e as formas como essas têm sido analisadas ao longo da história dos estudos sobre o lazer no Brasil.

Em relação a pouca divulgação e conhecimento sobre o "lazer sério", entendemos que pelo menos dois obstáculos poderiam se apresentar nas primeiras tentativas de incluir a "Perspectiva" nos debates brasileiros sobre o lazer. O primeiro se refere ao idioma em que estão disponibilizados os artigos e livros, o inglês. Embora o inglês seja considerado "universal", ele pode ser um impedimento para muitos leitores e estudiosos para quem o "lazer sério" poderia ser apresentado. Além disso, existem

\footnotetext{
${ }^{12}$ É possível visualizar pesquisadores envolvidos com a temática, bem como suas publicações envolvendo a "Perspectiva" ou algum de seus conteúdos. Disponível em: www.seriousleisure.net. Acesso em: 15 jan. 2014.
} 
muitos conceitos na obra de Stebbins que carecem de um rigoroso cuidado antes de sua tradução, pois suas representações poderiam gerar confusões graves e determinantes na apropriação de sua teoria.

Cabe aqui um breve comentário relativo ao presente artigo. Pretendemos apresentar mais uma possibilidade de análise do lazer, animando novos estudos e debates. Entendemos que é importante aos que intentam conhecer o "lazer sério" de forma aprofundada busquem conhecer as publicações em seu idioma original. Muitos aspectos interessantes e importantes estão contidos na obra de Robert A. Stebbins e atualmente não há qualquer tradução de um dos seus livros. As traduções propostas aqui devem ser consideradas provisórias e merecedoras de uma revisão rigorosa.

O segundo obstáculo que poderia ser encontrado, diz respeito à exigência de qualquer nova leitura ou perspectiva: disposição para compreensão de uma nova forma de olhar para o fenômeno que se pretende estudar. É possível verificar com o levantamento de estudos anteriormente descritos que a produção acadêmico-científica a partir da perspectiva do "lazer sério" é relativamente pequena no Brasil. Historicamente, os debates em torno do lazer no Brasil se fundamentam em estudos em que o lazer é colocado em contraposição ao trabalho.

Isso é certamente um ponto importante e, de fato, dominou nos estudos sobre o lazer por muito tempo, também fora do Brasil (PRAHL, 2002). O problema desta perspectiva é que ela pressupõe uma centralidade do trabalho na vida das pessoas que, desta forma, hoje nas sociedades contemporâneas é pelo menos questionável tendo em vista aspectos como desemprego, precarização das relações de trabalho (POCHMANN, 1999), centralidade do consumo (BAUMANN, 2007), aposentadoria, etc. Um conceito de lazer baseado na contraposição ao mundo de trabalho teria dificuldades de lidar com 
os grandes grupos de pessoas "não-trabalhadoras". Nesta situação, o conceito de "lazer sério" de Stebbins propõe uma outra perspectiva que busca compreender o fenômeno do lazer mais por uma perspectiva de dentro, assim oferecendo um referencial teórico diferente. Aqui seria necessário abrir um novo espaço para que a proposta de Stebbins pudesse ser compreendida e analisada.

Parece-nos que a proposta de Robert A. Stebbins não vai nem totalmente na contramão dos estudos tradicionais - considerando que posiciona o lazer em forte vinculação com o trabalho (compromisso, dedicação, seriedade, etc.) -, mas sim opera em uma via diferente de todos esses. Mas para podermos visualiza-la com bastante clareza e aproveitarmos disso, primeiro, será necessário abrirmos mão, por instantes, de nossas convicções para "ouvirmos" o que a teoria de Robert A. Stebbins tem a nos dizer.

O presente trabalho apresenta um pouco dessa obra como uma potente contribuição científica e faz-nos refletir sobre o desconhecimento e ausência de produções de autores como Stebbins no contexto brasileiro, apontando para necessidade de uma revisão crítica da vasta produção científica sobre lazer no Brasil. É bem possível que encontremos muitos limites de alcance da teoria, além dos brevemente mencionados aqui, assim como o é em outras. Bem como também é possível, ousamos dizer, que essa teoria contribua em algum sentido para ampliar nossas formas de olhar o lazer e ampliar nossos debates, permitindo que vejamos coisas ainda mais interessantes e, sobretudo, novas.

\section{REFERÊNCIAS}

ARAI, Susan; PEDLAR, Alison. Moving beyond individualism in leisure theory: A critical analysis of concepts of community and social engagement. Leisure Studies. v.22 p.185-202, 2003. 
BAUMANN, Zygmunt. Vida líquida. Rio de Janeiro: Zahar, 2007.

BRABHAM, Daren C. The myth of amateur crowds: a critical discourse analysis of crowdsourcing coverage. Information, Communication \& Society, v. 15, n. 3, p. 394410, 2012.

BRAMANTE, Carlos A. O lazer levado a sério. Agitação. São Paulo. CIEE Nacional, 1999.

CARNICELLI FILHO, S. 30 year of Serious Leisure. In: Leisure Studies Association Conference, 2012, Annals. Edinburgh. Leisure, Living, Learning: Education in Sport, Tourism, and the Outdoors. Edinburgh: LSA, v. 1. p. 29-30, 2012.

COSTA, Vera Lúcia de Menezes. Esportes de Aventura e Risco na Montanha: um mergulho no imaginário. São Paulo: Manole, 2000. 217 páginas

COSTA, Vera Lúcia de Menezes. Jogos com Limites e Incertezas: a aventura e o risco de esportistas na montanha. Corpus et Scientia, Rio de Janeiro. v. 1, n. 2, p. 17-29, 2005.

GOMES, C. M. Dumazedier e os Estudos do Lazer no Brasil: Breve Trajetória Histórica. In: SEMINÁRIO LAZER EM DEBATE, 9, 2008. Anais... São Paulo, USP/ Leste-CELAR/UFMG, 2008.

GOULD, James; et al. Development of the Serious Leisure Inventory and Measure.

Journal of Leisure Research. v.40, n.01, p.47-68, 2008.

LACERDA, Leonardo Lincoln Leite; VEIGA, Ricardo Teixeira. Museu e Marketing: elementos para a formação/atuação dos profissionais do lazer? Revista Brasileira de Ciências do Esporte, Campinas. v. 29, n. 3, p. 57-74, 2008.

OLIVEIRA, Saulo Neves. Lazer Sério e Envelhecimento: loucos por corrida. $101 \mathrm{f}$. Dissertação (Mestrado) - Programa de Pós-Graduação em Educação, UFRGS, Porto Alegre, 2010.

OLIVEIRA, Saulo Neves; DOLL, Johannes. Lazer Sério e Envelhecimento: dinâmicas em um grupo de corridas de rua. In: RIBEIRO, Jorge Alberto Rosa; RIBEIRO, Marlene. (Org.). Trabalho, Movimentos Sociais e Educação: redes de pesquisa. Porto Alegre: Itapuy, 2011. p. 312-324.

OLIVEIRA, Saulo Neves; DOLL, Johannes. Serious Leisure. Movimento (ESEF/UFRGS), v. 18, n. 1, p. 325-338, 2012.

PEIXOTO, Elza. Levantamento do estado da arte nos estudos do lazer:(Brasil) séculos XX e XXI: alguns apontamentos. Educação e Sociedade, v. 29, n. 99, p. 561-586, 2007.

POCHMANN, Márcio. Trabalho sob fogo cruzado: exclusão, desemprego e precarização no final do século. São Paulo: Contexto, 1999. 
PRAHL, Hans-Werner. Soziologie der Freizeit. Paderborn: Schöningh, 2002.

STADNIK, Adriana Maria Wan. Representações e práticas de professores universitários de educação física: quatro histórias de vida. $486 \mathrm{f}$. Tese (Doutorado) Instituto de Estudos da Criança, Universidade do Minho, Braga, 2008.

. A Prática da Ginástica Como um Lazer Sério. In: GAIO, R.; GOIS, A. A. F.; BATISTA, J. C. F. (Org.). A Ginástica em Questão: corpo e movimento. 2. ed. São Paulo: Phorte, 2010. p. 169-185

; CUNHA, António Camilo; PEREIRA, Beatriz . Ginástica geral: uma proposta para a educação física escolar. In: EDUCERE - CONGRESSO NACIONAL DE EDUCAÇÃO PUCPR - Práxis, 6, 2006, Curitiba. Anais... do EDUCERE - Curitiba: PUCPR, 2006. p. 861-874.

STEBBINS, Robert A. Serious Leisure. In: JENKINS, John; PIGRAM, John (Ed.). Encyclopedia of leisure and outdoor recreation. Routledge, 2003.

STEBBINS, Robert A. Serious Leisure. In: ROJEK, Chris; SHAW, Susan M.; VEAL, A.J. A. (Ed.). Handbook of Leisure Studies. New York: Palgrave Macmillan, 2006.

$156 \mathrm{f}$

Serious Leisure: a perspective for our time. New Jersey: Transaction, 2008.

The Idea of Leisure: first principles. New Jersey: Transaction, 2012.

STIGGER, M. P. Futebol de Veteranos: um estudo etnográfico sobre o esporte no cotidiano urbano. Movimento, Porto Alegre, v. 7, 1997.

Estudos Etnográficos sobre esporte e lazer: pressupostos teórico-metodológicos e pesquisa de campo. In: STIGGER, M. P.; GONZÁLEZ, F. J. SILVEIRA, R da. (Org.). Esporte na cidade: estudos etnográficos sobre sociabilidades esportivas em espaços urbanos. Porto Alegre: Editora da UFRGS, 2007.

TEIXEIRA, Heraldo Marconi da Costa. A Festa do Bumba-Meu-Boi da Maioba na Configuração do Estilo de Vida e Lazer. 135 f. Dissertação (Mestrado) - Programa de Pós-Graduação em Ciências da Motricidade, UNESP, Rio Claro, 2008.

TEIXEIRA, Heraldo Marconi da Costa. A Festa do Bumba-Meu-Boi da Maioba na Configuração do Estilo de Vida e Lazer. In: CONNEPI - CONGRESSO DE PESQUISA E INOVAÇÃO DA REDE NORTE E NORDESTE DE EDUCAÇÃO TECNOLÓGICA BELÉM, 4, Belém, 2009. Anais do CONNEPI, 2009.

.; et al. O lazer sério no cotidiano da festa popular do BUMBA-MEU-BOI. In: CONGRESSO INTERNACIONAL DE EDUCAÇÃO FÍSICA E MOTRICIDADE HUMANA, 5 e SIMPÓSIO PAULISTA DE EDUCAÇÃO FÍSICA, 11, 2007, Rio

Claro: Motriz, 2007. v. 13. p. 329-329. 
THE SERIOUS LEISURE PERSPECTIVE. Biography of Robert A. Stebbins. Canadá, 2011. Disponível em: $<$ http://www.seriousleisure.net/biography-of-robertastebbins.html >. Acesso em: 19 set. 2011.

UNRUH, David R. The nature of social worlds. Pacific Sociological Review. v.23, n.03, p.271-296, 1980.

\section{Endereço dos Autores:}

Saulo Neves de Oliveira

R. Atenas, 260, casa 29

Bairro Niterói

Canoas - RS - 9210-050

Endereço Eletrônico: sauloneves@ibest.com.br

Johannes Doll

R. Mata Bacelar, 280, apto 503

Bairro Auxiliadora

Porto Alegre - RS - 90540-150

Endereço Eletrônico: johannes.ufrgs@gmail.com 